\section{Burnout and Quality of Life among Active Member Physicians of the Medical Society of Sedgwick County}

Samuel Ofei-Dodoo, Ph.D., MPA, M.A.',

Rick Kellerman, M.D. ${ }^{1}$, Karissa Gilchrist, M.D. ${ }^{1,2}$,

Eastin M. Casey, M.D.,

${ }^{1}$ University of Kansas School of Medicine-Wichita,

Department of Family and Community Medicine

${ }^{2}$ University of Kansas School of Medicine-Wichita,

Family Medicine Residency Program at Ascension Via Christi

${ }^{3}$ University of Kansas School of Medicine-Wichita, Family Medicine Residency Program at Wesley Medical Center

Received Nov. 6, 2018; Accepted for publication January 16, 2019; Published online May 15, 2019

\begin{abstract}
Introduction. The medical literature suggests disturbingly high rates of burnout among US physicians. The objective of this study was to determine the rates of burnout, other forms of distress, and overall quality of life among physicians in Sedgwick County.

Methods. The study involved a convenience sample of 197 physicians who were active member physicians of the Medical Society of Sedgwick County (MSSC). Between July and August 2018, we surveyed 872 physicians who were active members of the MSSC. The survey assessed manifestations of burnout, symptoms of depression and suicidal ideation, fatigue, and quality of life. The authors used standard descriptive summary statistics, Mann-Whitney $U$ test/independent samples $t$-Test, Fisher's exact test, and correlations to analyze the data.
\end{abstract}

Results. The participation rate was $44.6 \%$, with $49.5 \%$ of the respondents reporting manifestations of burnout. Although $85 \%$ of the participants rated their overall quality of life as good/very good, $45 \%$ screened positive for depression, $5 \%$ had thoughts of suicide during the past year, and $44 \%$ reported excessive fatigue during the past week. Those with manifestations of burnout were 2.13 (100\% vs $46.9 \%, \mathrm{p}<0.01)$ times more likely to report thoughts of suicidal ideation, $2.43(72.6 \%$ vs $30.4 \%$; $\mathrm{p}<0.001)$ times more likely to screen positive for depression, and 1.89 (67.5\% vs 35.8\%; $\mathrm{p}<0.001)$ times more likely to have high degrees of fatigue. All of the participants who had suicidal ideation reported manifestations of burnout.

Conclusions. Burnout was prevalent among active member physicians of the MSSC. Burnout among the participants was associated with symptoms of depression, fatigue, suicidal ideation, and intention of leaving the medical profession via early retirement and/or career change. Kans J Med 2019;12(2):33-39.

\section{INTRODUCTION}

The medical literature suggests disturbingly high rates of burnout (physical or mental exhaustion caused by overwork or stress) in physicians and medical trainees. ${ }^{1-3}$ The Maslach Burnout Inventory commonly is used to evaluate professional burnout across three dimensions: emotional exhaustion, depersonalization, and personal accomplishment. As many as $54.3 \%$ of American physicians have at
KANSAS JOURNAL of MEDICINE

least one manifestation of professional burnout of emotional exhaustion and/or depersonalization, ${ }^{4}$ the generally accepted definition of burnout. Burnout among health care professionals has been associated with a decrease in the quality of patient care,,$^{5-7}$ an increase in the number of medical errors, ${ }^{4,-11}$ an elevated risk of suicidal ideation and depression,,${ }^{12,13}$ substance abuse, ${ }^{14}$ and a stronger intention of leaving the medical profession via early retirement and/or career change. ${ }^{15-18}$

A recent study of core faculty physicians of graduate medical education programs sponsored by the University of Kansas School of Medicine-Wichita (KUSM-W) found a $31 \%$ burnout rate among the participants. ${ }^{19}$ The current study was intended to determine how burnout rates, other forms of emotional distress (symptoms of depression, fatigue, suicidal ideation, and early retirement), and overall quality of life among active member physicians of the Medical Society of Sedgwick County (MSSC) compared to the rates of previously published data by Shanafelt et al. ${ }^{3,4}$ and Ofei-Dodoo et al. ${ }^{19}$

\section{METHODS}

Study Design and Participants. In July and August 2018, 872 physicians who were active members of the MSSC were surveyed. Each physician received an email invitation to participate in the study along with a link to a survey. Two reminders were sent over a period of two weeks. As a standard practice, ${ }^{13,20}$ the physicians who opened one of the email invitations were considered to have received the invitation to participate in the study. Overall, 442 physicians opened at least one of the email invitations and were considered to have received the invitation to participate. Participation was voluntary and responses were anonymous. A sample size of 180 was calculated as necessary for adequate power $(>0.85)$ to detect significant group differences between the variables with 0.05 effect size and $\mathrm{p}<0.05 .{ }^{21}$ The KUSM-W Institutional Review Board granted exemption for the study.

Outcome Measures. The survey included items on burnout, symptoms of depression, suicidal ideation, fatigue, quality of life, intention to retire early or change careers, and demographic information (sex, age, number of hours worked per week, and specialty).

Rates of burnout among participants were measured using the Abbreviated Maslach Burnout Inventory (MBI-9), a validated 9-item questionnaire considered a criterion tool to measure manifestations of burnout. ${ }^{22-24}$ The inventory assesses professional burnout across three dimensions: emotional exhaustion, depersonalization, and perception of personal accomplishment. Participants recorded their feeling about work-related burnout on a 7-point rating scale ranging from "never" to "every day." Scores for the three questions specific to each of the Maslach dimensions were summed with a possible score ranging from zero to 18 .

Consistent with convention, ${ }^{24,25}$ the scores of each dimension were grouped into low, intermediate, and high burnout categories. For the emotional exhaustion and depersonalization dimensions, higher scores are indicative of greater emotional exhaustion and depersonalization, and greater burnout. For the personal accomplishment 
KANSAS JOURNAL of MEDICINE BURNOUT AND QUALITY OF LIFE AMONG PHYSICIANS

continued.

dimension, higher scores indicate a greater sense of personal accomplishment, and less burnout. As a standard practice, ${ }^{24-26}$ physicians who scored high on emotional exhaustion ( $\geq 11)$ and/or depersonalization $(\geq 7)$ were considered to have at least one manifestation of professional burnout.

The 2-item Primary Care Evaluation of Mental Disorders (PRIME MD) Patient Health Questionnaire (PHQ)-2 depressionscreening questions asked the participants about their feelings of being down, depressed, or hopeless and if they have been bothered by little interest or pleasure in usual activities. The 2-question screen has reported sensitivity and specificity for depression of $96 \%$ and $57 \%$ respectively. ${ }^{27,28}$ The question, "During the past 12 months, have you had thoughts of taking your own life?" was used to assess suicidal ideation among the physicians. The question has been used in previous studies involving physicians and medical students. ${ }^{12,13,29,30}$

The physicians' overall quality of life was measured using a single global item from the World Health Organization Quality of Life (WHOQOL)-BREF. ${ }^{31}$ Participants rated their overall quality of life on a 5-point Likert scale ranging from "very poor" to "very good" with score of " 5 " representing "very good."

The physicians' levels of fatigue were measured during the prior week using a standardized linear analogue scale $(0=$ as bad as it can be to $10=$ as good as it can be) similar to what was described by West et al. ${ }^{32}$ Lower scores on the scale indicate higher levels of fatigue. Participants who scored five or less on the scale were considered to have higher levels of fatigue. ${ }^{13,33}$

Regarding the participants' intentions of leaving the medical profession through early retirement and/or career change, a 3-item scale from Boshoff and Allen (2000) $)^{34}$ was used with slight modification. All items were measured on a 5-point Likert scale ranging from "strongly disagree" to "strongly agree." The composite score was calculated by summing up the item scores for analysis. Higher scores indicated a stronger intention of leaving the medical profession through early retirement and/or career change.

Statistical Analysis. Standard descriptive statistics were calculated to create a demographic profile and describe the prevalence of burnout manifestation among the participants. Mann-Whitney $U$ test/independent samples $t$-Test (for continuous variables), Fisher's exact test (for categorical variables), and correlation were used to evaluate the association between the variables. A critical value of 0.05 was specified for all inferential statistics.

\section{RESULTS}

Of the 442 physicians who opened the email invitation, 197 completed all or most of the survey for a participation rate of $44.6 \%$. The demographic characteristics of responding physicians are shown in Table 1. Analysis of the study sample compared to the overall MSSC population of active members showed a margin of error of $+/-6.2$ percentage points at a $95 \%$ confidence level, demonstrating that the demographic characteristics of this study generally represented the overall MSSC population of active members. ${ }^{35}$
Table 2 summarizes the respondents' characteristics in relation to manifestations of burnout, symptoms of depression, suicidal ideation in the past 12 months, level of fatigue in the past week, and quality of life. Using the MBI-9 for assessment, $45.7 \%$ of 186 physician respondents reported high emotional exhaustion, $26.9 \%$ high depersonalization, and $18.3 \%$ low sense of personal accomplishment. In aggregate, $49.5 \%$ of the 186 respondents reported manifestations of burnout. A higher percentage of male physicians reported manifestations of burnout than female physicians ( $54.3 \%$ vs. $43.5 \%$ ).

Nearly $85 \%$ of the participants rated their overall quality of life as good/very good. A total of $44.5 \%$ screened positive for depression, $4.7 \%$ had thoughts of suicidal ideation over the past year, and $40.6 \%$ reported excessive fatigue over the last week. The overall quality of life was dichotomized into good quality of life (combination of "very good" and "good" responses) and poor quality of life (combination of "neither poor nor good," "poor" and "very poor" responses). The Fisher's exact test was used to calculate the relationship between the variables. The physicians with good quality of life were less likely than those with poor quality of life to report manifestations of burnout (43.1\% vs $88.5 \%, \mathrm{p}<0.001$ ), screen positive for depression (36.4\% vs $96.2 \%, \mathrm{p}<0.001)$, and complain of fatigue (36.0\% vs $80.8 \%$, p < $0.001)$.

As shown in Table 3, the nine responding physicians who reported suicidal ideation had manifestations of burnout. Those with manifestations of burnout were 2.13 (100\% vs 46.9\%, p < 0.01 ) times more likely to report thoughts of suicidal ideation, 2.43 (72.6\% vs 30.4\%; $\mathrm{p}<0.001)$ times more likely to screen positive for depression, 1.89 (67.5\% vs $35.8 \%$; $<$ 0.001) times more likely to have high degrees of fatigue, and $1.43(54.7 \%$ vs $38.2 \%)$ times more likely to work over 50 hours per week.

Table 4 shows that the physician respondents who reported manifestations of burnout $(10.41 \pm 3.20$ vs $6.60 \pm 3.61, \mathrm{p}<0.001)$, screened positive for depression ( $10.60 \pm 3.43$ vs $6.74 \pm 3.37$, p $<0.001)$, complained of excessive fatigue (10.62 \pm 3.25 vs $6.88 \pm 3.57$, p $<0.001)$, and had suicidal thoughts ( $11.78 \pm 8.31$ vs $8.31 \pm 3.87, \mathrm{p}<0.01$ ), reported stronger intentions of leaving the medical profession.

Results on Specialties. Given that a plurality of the respondents were family physicians (24.4\% [ 48 of 197]), data on family medicine was compared with all other specialties combined. There was no statistical difference between the groups on any variable.

Data on surgical specialties were compared with non-surgical specialties on manifestations of burnout, symptoms of depression, and suicidal ideation. The surgical specialties included anesthesiology, obstetrics and gynecology, ophthalmology, orthopedic surgery, and otolaryngology. The non-surgical specialties comprised of dentistry, dermatology, emergency medicine, family medicine, general practice, hospitalist, internal medicine, neurology, pathology, pediatrics, physical medicine and rehabilitation, psychiatry, radiation oncology, radiology, and others. There was no statistical relationship between the specialties on the variables. 
Table 1. Demographic characteristics of responding physicians.

\begin{tabular}{|c|c|}
\hline Characteristics & Participants $(n=197)$ \\
\hline \multicolumn{2}{|l|}{ Sex, No. (\%) } \\
\hline Male & $106(53.8)$ \\
\hline Female & $77(39.1)$ \\
\hline Missing & $14(7.1)$ \\
\hline \multicolumn{2}{|l|}{ Age, years } \\
\hline Age group, No. (\%) & $(\mathrm{n}=184)$ \\
\hline $25-34$ & $8(4.3)$ \\
\hline $35-44$ & $54(29.3)$ \\
\hline $45-54$ & $46(25.0)$ \\
\hline $55-64$ & $54(29.3)$ \\
\hline$\geq 65$ & $22(12.0)$ \\
\hline \multicolumn{2}{|l|}{ Years in Practice, No. (\%) } \\
\hline $1-9$ & 37 (18.8) \\
\hline $10-19$ & $59(29.9)$ \\
\hline $20-29$ & $44(22.3)$ \\
\hline$\geq 30$ & $41(20.8)$ \\
\hline Missing & $16(8.1)$ \\
\hline \multicolumn{2}{|l|}{ Hours worked per week } \\
\hline \multicolumn{2}{|l|}{ Range, No. $(\%)$} \\
\hline$<40$ & $17(8.6)$ \\
\hline $40-49$ & $38(19.3)$ \\
\hline $50-59$ & $59(29.9)$ \\
\hline $60-69$ & 39 (19.8) \\
\hline $70-79$ & $13(6.6)$ \\
\hline$\geq 80$ & $17(8.6)$ \\
\hline Missing & $14(7.1)$ \\
\hline \multicolumn{2}{|l|}{ Specialty, No. (\%) } \\
\hline Anesthesiology & $5(2.5)$ \\
\hline Dentistry & $1(0.5)$ \\
\hline Dermatology & $1(0.5)$ \\
\hline Emergency medicine & $7(3.6)$ \\
\hline Family medicine & $48(24.4)$ \\
\hline General practice & $1(0.5)$ \\
\hline Hospitalist & $11(5.6)$ \\
\hline Internal medicine sub-specialty & $12(6.1)$ \\
\hline Internal medicine-general & $12(6.1)$ \\
\hline Neurology & $3(1.5)$ \\
\hline Obstetrics and gynecology & $13(6.6)$ \\
\hline Ophthalmology & $4(2.0)$ \\
\hline Orthopedic surgery & $2(1.0)$ \\
\hline Otolaryngology & $4(2.0)$ \\
\hline Pathology & $4(2.0)$ \\
\hline Pediatric subspecialty & $6(3.0)$ \\
\hline Pediatrics-general & $13(6.6)$ \\
\hline Physical medicine and rehabilitation & $1(0.5)$ \\
\hline Psychiatry & $8(4.1)$ \\
\hline Radiation oncology & $1(0.5)$ \\
\hline Radiology & $4(2.0)$ \\
\hline Surgery & $15(7.6)$ \\
\hline Other & $7(3.6)$ \\
\hline Missing & $14(7.1)$ \\
\hline
\end{tabular}

KANSAS JOURNAL of MEDICINE

BURNOUT AND QUALITY OF LIFE AMONG

\section{PHYSICIANS}

continued.

\section{DISCUSSION}

Collectively, this study illustrated that the prevalence of burnout and other forms of distress (symptoms of depression, fatigue, and suicidal ideation) are at troubling levels among active member physicians of the MSSC. The burnout rate of 49.5\% among MSSC active members was comparable with published rates among other practicing US physicians (50.5\% - 54.4\%). ${ }^{3,4,36}$

The rate of burnout among the MSSC active members was higher than the $31 \%$ rate reported among core faculty physicians in the KUSM-W community-based graduate medical education system. ${ }^{19}$ Large numbers of Wichita community physicians who are MSSC members volunteer to teach in the KUSM-W system and hold volunteer faculty appointments. Full-time paid KUSM-W faculty physicians tend to have fewer clinical responsibilities, provide less direct patient care, and take on more academic responsibilities, such as didactic teaching, resident evaluation, administrative work, and scholarly activities, than community physicians. It is probable that some core KUSM-W faculty physicians were included in the MSSC survey. The manifestations of burnout may be even higher among the community faculty than reported in the MSSC survey because of the inclusion of full-time paid KUSM-W faculty physicians.

High physician burnout rates were correlated with symptoms of depression, fatigue, suicidal ideation, and intention of leaving the medical profession via early retirement and/or career change. The definition of these variables undoubtedly overlap. Several other studies have found an association between physician burnout and an increase in the risk of suicidal ideation as well as risk of depression ${ }^{12,13}$ and stronger intention of leaving the medical profession through early retirement and/or career change. ${ }^{15-18}$

There is evidence that physician burnout is associated with a decrease in the quality of patient care. ${ }^{5-7}$ Given this evidence, physician burnout threatens the safety and effectiveness of the US medical system. Much attention has been focused on the causes of burnout among physicians. The stress of patient care, demanding patients, risk of medical liability, personal and psychologic characteristics of physicians, environmental, institutional and health care delivery system factors, and the culture of medicine have been implicated. ${ }^{19,37}$ The electronic medical record and the administrative burden of practicing medicine (i.e., paperwork) commonly are cited contributions to burnout. 19,37 The breakdown of social camaraderie among physicians may contribute to physician burnout. As many physicians no longer see patients regularly in the hospital setting, opportunities to meet informally "in the doctor's lounge" and "curbstone consult" their colleagues about patient problems are lost. 
Table 2. Burnout, depression, suicidal ideation, fatigue, and quality of life among 197 MSSC active members.

\begin{tabular}{|c|c|c|c|}
\hline Variable & $\begin{array}{l}\text { All Participants } \\
(n=197)\end{array}$ & $\begin{array}{c}\text { Male } \\
(n=106) \\
\end{array}$ & $\begin{array}{l}\text { Female } \\
(\mathrm{n}=77)\end{array}$ \\
\hline \multicolumn{4}{|c|}{ Burnout Index ${ }^{a}$} \\
\hline \multicolumn{4}{|l|}{ Emotional Exhaustion } \\
\hline Median score & 9.0 & 9.0 & 11.0 \\
\hline Score level, No. (\%) & $(n=186)$ & $(\mathrm{n}=106)$ & $(n=77)$ \\
\hline Low & $58(31.2)$ & $41(38.7)$ & $16(20.8)$ \\
\hline Intermediate & $43(23.1)$ & $22(20.8)$ & $21(27.3)$ \\
\hline High & $85(45.7)$ & $43(40.6)$ & $40(51.9)$ \\
\hline \multicolumn{4}{|l|}{ Depersonalization } \\
\hline Median score & 3.0 & 3.0 & 3.0 \\
\hline Score level, No. (\%) & $(\mathrm{n}=186)$ & $(n=106)$ & $(\mathrm{n}=77)$ \\
\hline Low & $102(54.8)$ & $59(55.7)$ & $42(54.5)$ \\
\hline Intermediate & $34(18.3)$ & $17(16.0)$ & $16(20.8)$ \\
\hline High & $50(26.9)$ & $30(28.3)$ & $19(24.7)$ \\
\hline \multicolumn{4}{|l|}{ Personal Accomplishment } \\
\hline Median score & 16.0 & 16.0 & 15.0 \\
\hline Score level, No. (\%) & $(\mathrm{n}=186)$ & $(\mathrm{n}=106)$ & $(n=77)$ \\
\hline High & $120(64.5)$ & $15(14.2)$ & $18(23.4)$ \\
\hline Intermediate & $32(17.2)$ & $20(18.9)$ & $12(15.6)$ \\
\hline Low & $34(18.3)$ & $71(67.0)$ & $47(61.0)$ \\
\hline Burnout, No. $(\%)^{b}$ & $92(49.5)$ & $50(54.3)^{Y}$ & $40(43.5)^{Y}$ \\
\hline \multicolumn{4}{|c|}{ Depression } \\
\hline Screen positive for depression, No. (\%) & $85(44.5)$ & $43(40.6)$ & $39(50.6)$ \\
\hline \multicolumn{4}{|c|}{ Suicidal Ideation } \\
\hline In the past 12 months, No. (\%) & $9(4.7)$ & $5(4.7)$ & $4(5.2)$ \\
\hline \multicolumn{4}{|c|}{ Fatigue } \\
\hline \multicolumn{4}{|l|}{ Level of fatigue in the past week } \\
\hline Mean $(\mathrm{SD})^{\mathrm{c}}$ & $6.1(2.1)$ & $1.6(0.49)$ & $1.5(0.50)$ \\
\hline Low & $110(55.8)$ & $67(63.2)$ & $38(49.4)$ \\
\hline High & $80(40.6)$ & $39(36.8)$ & $39(50.6)$ \\
\hline Missing & $7(3.6)$ & & \\
\hline \multicolumn{4}{|c|}{ Quality of Life } \\
\hline \multicolumn{4}{|c|}{ How would you rate your overall quality of life? } \\
\hline Very poor & --- & --- & --- \\
\hline Poor & $11(5.6)$ & $4(3.8)$ & $7(9.1)$ \\
\hline Neither poor nor good & $15(7.6)$ & $6(5.7)$ & $9(11.7)$ \\
\hline Good & $95(48.2)$ & $49(46.2)$ & $37(48.1)$ \\
\hline Very good & $72(36.5)$ & $47(44.3)$ & $24(31.2)$ \\
\hline Missing & $4(2.0)$ & --- & --- \\
\hline
\end{tabular}

${ }^{a}$ Assessed using the Abbreviated Maslach Burnout Inventory (MBI-9). Per standard scoring, scores of $\geq 7$ on the Depersonalization doman, $\geq 11$ on Emotional Exhaustion domain, or $\leq 12$ on Personal Accomplishment domain are considered to be high scores on that dimension.

bHigh score on Emotional Exhaustion and/or Depersonalization subscale of the MBI-9.

'Low mean fatigue score suggests higher/worsened fatigue.

${ }^{\ddagger}$ Data do not add up to $100 \%$ because of missing responses. 
Table 3. Relationship of suicidal ideation, depression, and fatigue to burnout.

\begin{tabular}{|l|c|c|c|c|c|c|}
\hline \multicolumn{1}{|c|}{ Measures } & \multicolumn{2}{|c|}{ Burnout } & & \\
\hline & Present & Not Present & Total & $\chi^{2}$ & p value & Phi \\
\hline Suicidal Ideation, no. (\%) & & & & 9.67 & $<0.01$ & 0.228 \\
\hline Yes & $9(100.0)$ & $0(0.0)$ & $9(100.0)$ & & & \\
\hline No & $83(46.9)$ & $94(53.1)$ & $177(100.0)$ & & & \\
\hline Total & $92(49.5)$ & $94(50.5)$ & $186(100.0)$ & & & \\
\hline Screened for Depression, no. (\%) & & & & 32.9 & $<0.001$ & 0.42 \\
\hline Positive for depression & $61(72.6)$ & $23(27.4)$ & $84(100.0)$ & & & \\
\hline Negative for depression & $31(30.4)$ & $71(69.6)$ & $102(100.0)$ & & & \\
\hline Total & $92(49.5)$ & $94(50.5)$ & $186(100.0)$ & & & \\
\hline Level of Fatigue, no. (\%) & & & & 18.27 & $<0.001$ & 0.313 \\
\hline High degree & $54(67.5)$ & $26(32.5)$ & $80(100.0)$ & & & \\
\hline Low degree & $38(35.8)$ & $68(64.2)$ & $106(100.0)$ & & & \\
\hline Total & $92(49.5)$ & $94(50.5)$ & $186(100.0)$ & & & \\
\hline Hours worked per week, no. (\%) & & & 4.19 & $<0.05$ & 0.15 \\
\hline$\leq 50$ hours & $21(38.2)$ & $34(61.8)$ & $55(100.0)$ & & & \\
\hline$>50$ hours & $70(54.7)$ & $58(45.3)$ & $128(100.0)$ & & & \\
\hline Total & $91(49.7)$ & $92(50.3)$ & $183(100.0)$ & & & \\
\hline
\end{tabular}

Table 4. Association of burnout, depression, fatigue, and suicidal ideation with intention of leaving the medical profession.

\begin{tabular}{|l|c|c|c|c|c|c|c|}
\hline \multirow{2}{*}{ Measure } & \multicolumn{7}{|c|}{ Intention of Leaving the Medical Profession } \\
\cline { 2 - 8 } & $\mathbf{n}$ & Mean & SD & Test Statistic & $\mathbf{9 5 \%}$ CI & Cohen's d & p value \\
\hline Burnout manifestation & & & & $t(182)=7.57$ & 2.81 to 4.80 & 3.35 & $<0.001$ \\
\hline Present & 91 & 10.41 & 3.20 & & & & \\
\hline Not present & 93 & 6.60 & 3.61 & & & & \\
\hline Depression & & & & $t(182)=7.66$ & 2.87 to 4.85 & 1.35 & $<0.001$ \\
\hline Screened positive & 83 & 10.60 & 3.43 & & & & \\
\hline Screened negative & 101 & 6.74 & 3.37 & & & & \\
\hline Fatigue & & & & $t(182)=7.31$ & 2.73 to 2.75 & 1.09 & $<0.001$ \\
\hline High degree & 79 & 10.62 & 3.25 & & & & \\
\hline Low degree & 105 & 6.88 & 3.57 & & & & \\
\hline Suicidal Ideation & & & & $t(182)=7.31$ & 0.88 to 3.05 & 2.64 & $<0.01$ \\
\hline Yes & 9 & 11.78 & 3.03 & & & & \\
\hline No & 175 & 8.31 & 3.87 & & & & \\
\hline
\end{tabular}

Note: $\mathrm{n}$ = sample size; $\mathrm{SD}=$ Standard Deviation; $\mathrm{CI}=$ Confidence Interval

aThe range of the composite scores was 3 - 15.

bHigher mean scores indicate stronger intentions of leaving the medical profession through early retirement and/or career change. 
KANSAS JOURNAL of MEDICINE

BURNOUT AND QUALITY OF LIFE AMONG

PHYSICIANS

continued.

Physician participation in activities that promote wellness, such as exercise and mindfulness activities, healthier eating, decompression from daily stress, and connecting with others within and outside work, has been suggested as a strategy to counteract burnout. ${ }^{19}$ Policy makers and health care organizations have a part to play in mitigating physician burnout. ${ }^{38}$ Improved recognition of burnout and development of resources to address the problem within hospital systems and other health care-related organizations, such as insurance companies, government, and organized medicine, are necessary.

In the burnout study of KUSM-W residents and faculty members, Ofei-Dodoo and colleagues ${ }^{19}$ found that work-life imbalance (e.g., excessive workload, system issues such as inefficient electronic medical record systems, excessive documentation requirements, and administrative burden) and poor leadership were some of the major causes of burnout.

Prior research in Egypt associated poor quality of life to distress among physicians. ${ }^{43}$ Our findings showed that a significant majority (approximately 85\%) of respondent physicians reported good/very good overall quality of life despite half reporting manifestations of burnout. Quality of life is a subjective multidenominational construct that includes emotional, mental, social, physical health, and economic domains. ${ }^{39-42}$ The respondent physicians may have interpreted their quality of life in a limited number of domains, such as socioeconomic status or personal health. Further research would be helpful to define this finding among US physicians, especially because our study used only a single global rating question to characterize quality of life.

This study is subject to several limitations. First, about half of the physicians did not open the message or did not receive the invitation to participate in the study. Of those who opened the survey, the $44 \%$ participation rate is consistent with other physician studies. ${ }^{2,12,13,19}$ Second, as this study's results are limited to active member physicians of the MSSC, the findings may not be generalizable to physicians in other communities. Third, given that the study was nonexperimental, causal relationships between the variables could not be determined. Additionally, a short-form and screening questions were used rather than long-form or diagnostic criteria to characterize the variables. For example, the PHQ-2 screening questions were used rather than the PHQ-9 questions, other depression screening surveys, or diagnostic interviews.

In conclusion, burnout was prevalent among active member physicians of the Medical Society of Sedgwick County. Burnout among the participant physicians is associated with symptoms of depression, fatigue, suicidal ideation, and intention of leaving the medical profession via early retirement and/or career change. Given the distress of burnout and potential impact on patient care, serious attention should be devoted to this problem. Interventions to address the problem should be holistic and include personal, educational, organizational, environmental, and cultural interventions.

\section{ACKNOWLEDGEMENTS}

The authors thank Mr. Phillip Brownlee of the Medical Society of Sedgwick County for the support and invaluable feedback on the manuscript.

\section{REFERENCES}

${ }^{1}$ Ishak WW, Lederer S, Mandili C, et al. Burnout during residency training: A literature review. J Grad Med Educ 2009; 1(2):236-242. PMID: 21975985.

${ }^{2}$ Shanafelt TD, Boone S, Tan L, et al. Burnout and satisfaction with worklife balance among US physicians relative to the general US population. Arch Intern Med 2012; 172(18):1377-1385. PMID: 22911330.

3 Shanafelt TD, Hasan O, Dyrbye LN, et al. Changes in burnout and satisfaction with work-life balance in physicians and the general US working population between 2011 and 2014. Mayo Clin Proc 2015; 90(12):16001613. PMID: 26653297.

4 Tawfik DS, Profit J, Morgenthaler TI, et al. Physician burnout, well-being, and work unit safety grades in relationship to reported medical errors. Mayo Clin Proc 2018; 93(11):1571-1580. PMID: 30001832.

${ }^{5}$ Dewa CS, Loong D, Bonato S, Trojanowski L. The relationship between physician burnout and quality of healthcare in terms of safety and acceptability: A systematic review. BMJ Open 2017; 7(6):e015141. PMID: 28637730. ${ }^{6}$ Weigl M, Schneider A, Hoffmann F, Angerer P. Work stress, burnout, and perceived quality of care: A cross-sectional study among hospital pediatricians. Eur J Pediatr 2015; 174:1237-1246. PMID: 25846697.

7 Shirom A, Nirel N, Vinokur AD. Overload, autonomy, and burnout as predictors of physicians' quality of care. J Occup Health Psychol 2006; 11(4):328-342. PMID: 17059297.

${ }^{8}$ Klein J, Grosse Frie K, Blum K, von dem Knesebeck O. Burnout and perceived quality of care among German clinicians in surgery. Int J Qual Health Care 2010; 22(6):525-530. PMID: 20935011.

${ }^{9}$ Hayashino Y, Utsugi-Ozaki M, Feldman MD, Fukuhara S. Hope modified the association between distress and incidence of self-perceived medical errors among practicing physicians: Prospective cohort study. PLoS One 2012; 7(4):e35585. PMID: 22530055.

${ }_{10}$ Wen J, Cheng Y, Hu X, Yuan P, Hao T, Shi Y. Workload, burnout, and medical mistakes among physicians in China: A cross-sectional study. Biosci Trends 2016; 10(1):27-33. PMID: 26961213.

${ }^{11}$ Shanafelt TD, Balch CM, Bechamps G, et al. Burnout and medical errors among American surgeons. Ann Surg 2010; 251(6):995-1000. PMID: 19934755.

12 Dyrbye LN, Thomas MR, Massie FS, et al. Burnout and suicidal ideation among U.S. medical students. Ann Intern Med 2008; 149(5):334-341. PMID: 18765703.

${ }^{13}$ Dyrbye LN, West CP, Satele D, et al. Burnout among U.S. medical students, residents, and early career physicians relative to the general U.S. population. Acad Med 2012; 89(3):443-451. PMID: 24448053.

14 Dyrbye LN, Massie FS, Eacker A, et al. Relationship between burnout and professional conduct and attitudes among US medical students. JAMA 2010; 304(11):1173-1180. PMID: 20841530.

15 Dewa CS, Jacobs P, Thanh NX, Loong D. An estimate of the cost of burnout on early retirement and reduction in clinical hours of practicing physicians in Canada. BMC Health Serv Res 2014; 14:254. PMID: 24927847.

16 Soler JK, Yaman H, Esteva M, et al. Burnout in European family doctors: The EGPRN study. Fam Pract 2008; 14(4):245-265. PMID: 18622012.

17 Hoff T, Whitcomb WF, Nelson JR. Thriving and surviving in a new medical career: The case of hospitalist physicians. J Health Soc Behav 2002; 14(1):72-91. PMID: 11949198.

${ }_{18}$ Zhang Y, Feng X. The relationship between job satisfaction, burnout, and turnover intention among physicians from urban state-owned medical institutions in Hubei, China: A cross-sectional study. BMC Health Serv Res 2011; 14:235. PMID: 21943042.

19 Ofei-Dodoo S, Callaway P, Engels K. Prevalence and etiology of burnout in a community-based graduate medical education system: A mixed method study. Family Medicine 2019; in press.

20 American Association for Public Opinion Research. Standard Definitions: Final Dispositions of Case Codes and Outcome Rates for Surveys. https://www.esomar.org/what-we-do/code-guidelines/ AAPOR-Standard-Definitions-Final-Dispositions-of-Case-Codes-andOutcome-Rates-for-Surveys. Accessed September 5, 2018.

${ }^{21}$ Australia and New Zealand Melanoma Trials Group Statistical Decision Tree. Power calculator for independent t-test or paired t-test. https://www. anzmtg.org/stats/Power Calculator/PowerTtest. Accessed October 8, 2018. 
22 McManus IC, Keeling A, Paice E. Stress, burnout and doctors' attitudes to work are determined by personality and learning style: A twelve year longitudinal study of UK medical graduates. BMC Med 2004; 2:29. PMID: 15317650 .

${ }^{23}$ Maslach C, Leiter MP. Early predictors of job burnout and engagement. J Appl Psychol 2008; 93(3):498-512. PMID: 18457483.

${ }^{24}$ Sotile Center for Resilience. Maslach Burnout Inventory (Abbreviated) - MBI-9. https://www.nzgp-webdirectory.co.nz/site/nzgp-webdirectory2/ Burnout-Abbreviated-General.pdf. Accessed on April 4, 2018.

${ }^{25}$ Maslach C, Jackson SF, Leiter MP. Maslach Burnout Inventory Manual. 3rd Ed. Palo Alto, CA: Consulting Psychologists Press, 1996.

${ }^{26}$ Scaufeli WB, Bakkar AB, Hoogduin K, Schaap C, Kladler A. On the clinical validity of Maslach burnout inventory and the burnout measure. Psychol Health 2001; 16(5):565-582. PMID: 22804499.

${ }^{27}$ Whooley MA, Avins AL, Miranda J, Browner WS. Case-finding instruments for depression. Two questions are as good as many. J Gen Intern Med 1997; 12(7):439-445. PMID: 9229283.

${ }^{28}$ Spitzer RL, Williams JB, Kroenke K, et al. Utility of a new procedure for diagnosing mental disorders in primary care. The PRIME-MD 1000 study. JAMA 1994; 272(22):1749-1756. PMID: 7966923.

29 Shanafelt TD, Balch CM, Dyrbye LN, et al. Special report: Suicidal ideation among American surgeons. Arch Surg 2011; 146(1):54-62. PMID: 21242446.

${ }^{30}$ van der Heijden F, Dillingh G, Bakker A, Prins J. Suicidal thoughts among medical residents with burnout. Arch Suicide Res 2008; 12(4):344-346. PMID: 18828037.

${ }^{31}$ World Health Organization. Programme on Mental Health. WHOQOLBREF: introduction, administration, scoring, and generic version of the assessment. Geneva: World Health Organization, 1996.

32 West CP, Tan AD, Habermann TM, Sloan JA, Shanafelt TD. Association of resident fatigue and distress with perceived medical errors. JAMA 2009; 302(12):1294-1300. PMID: 19773564.

33 Sloan JA, Zhao X, Novotny PJ, et al. Relationship between deficits in overall quality of life and non-small-cell lung cancer survival. J Clin Oncol 2012; 30(13):1498-1504. PMID: 22454418.

${ }^{34}$ Boshoff C, Allen J. The influence of selected antecedents on frontline staff's perceptions of service recovery performance. Int J Serv Industry Manag 2000;11:63-90.

35 Data Star, Inc. What Every Researcher Should Know About Statistical Significance. October 2008. http://www.surveystar.com/startips/oct2008. pdf. Accessed October 8, 2018.

36 Dyrbye LN, Varkey P, Boone SL, Satele DV, Sloan JA, Shanafelt TD. Physician satisfaction and burnout at different career stages. Mayo Clin Proc 2013; 88(12):1358-1367. PMID: 24290109.

37 Shanafelt TD, Sloan JA, Habermann TM. The well-being of physicians. Am J Med 2003; 114(6):5l3-519. PMID: 12727590.

38 Dyrbye LN, Shanafelt TD. Physician burnout: A potential threat to successful health care reform. JAMA 2011; 305(19):2009-2010. PMID: 21586718.

39 The WHOQOL Group. The World Health Organization Quality of Life Assessment (WHOQOL): Development and psychometric properties. Soc Sci Med 1998; 46(12):1569-1585. PMID: 9672396.

${ }^{40}$ Centers for Disease Control and Prevention. Measuring healthy days: Population assessment of health-related quality of life. Atlanta, Georgia: Centers for Disease Control and Prevention, 2000.

${ }^{41}$ Gandek B, Sinclair SJ, Kosinski M, Ware JE Jr. Psychometric evaluation of the SF-36 health survey in Medicare managed care. Health Care Financ Rev 2004; 25(4):5-25. PMID: 15493441.

${ }^{42}$ McHorney CA. Health status assessment methods for adults: past accomplishments and future directions. Annual Rev Public Health 1999; 20:309-335. PMID: 10352861.

${ }^{43}$ Farahat TM, Hegazy HN, Mohamed DH. Burnout and quality of life among physicians in primary healthcare facilities in Egypt: A cross-sectional study. Menoufia Med J 2017; 30(3):789-793.

Keywords: professional burnout, depression, suicidal ideation, quality of life, physicians
KANSAS JOURNAL of MEDICINE

BURNOUT AND QUALITY OF LIFE AMONG

PHYSICIANS

continued. 